\title{
COMMUNICATION
}

\section{A Simple Access to Transition Metal Cyclopropenylidene Complexes}

\author{
Yannick D. Bidal ${ }^{a}$, Mathieu Lesieur ${ }^{a}$, Mohand Melaimi ${ }^{b}$, David B. Cordes ${ }^{a}$, \\ Alexandra M. Z. Slawin ${ }^{a}$, Guy Bertrand ${ }^{*}$ and Catherine S. J. Cazin ${ }^{a}$
}

Received ooth January 2012,

Accepted ooth January 2012

DOI: $10.1039 /$ xoxxooooox

www.rsc.org/

We report the first example of $\mathrm{BAC}-\mathrm{Cu}$ complex $(\mathrm{BAC}=$ bis(diisopropylamino)cyclopropenylidene) and its use as a carbene-transfer reagent, allowing access to Au-, Pd-, Ir- and Rh-BAC compounds. Catalytic experiments show the high activity of the $[\mathrm{CuCl}(\mathrm{BAC})]$ complex in Click chemistry.

Cyclopropenylidenes, the simplest aromatic ring system displaying a carbene centre, are amongst the most discussed compounds within the carbocyclic carbene family. ${ }^{1}$ Since the early 1970 's, ${ }^{1 a}$ various transition metal complexes bearing cyclopropenylidene ligands have been prepared. Their synthesis has been achieved via oxidative addition of dihalocyclopropenes, ${ }^{2 \mathrm{~d}-\mathrm{f}, 3}$ by the reaction of cyclopropenium salts or lithium adducts, ${ }^{2 \mathrm{~d}-\mathrm{f}, 4}$ or using deoxygenation, desulfurization and deselenization routes. $^{2 \mathrm{e}, 5}$ However these methodologies require harsh conditions that are not conducive to the generation of libraries of complexes. ${ }^{1 \mathrm{a}}$ The isolation of the cyclopropenylidene 1 in $2006^{6}$ (Scheme 1) allowed to broaden the number of complexes available, ${ }^{1 \mathrm{a}, 7}$ but Group 11 remains to date scarcely studied, with no example of gold and copper compounds, and only one example of a silver derivative. ${ }^{8}$ As a consequence, the catalytic activity of cyclopropenylidene metal complexes has

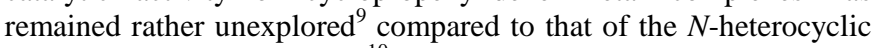
carbene (NHC) counterparts. ${ }^{10}$

As part of our ongoing efforts to develop straightforward synthetic accesses to NHC transition metal complexes, we have shown that $\mathrm{Cu}-\mathrm{NHC}$ compounds could be obtained by simple reaction of the conjugate acid of NHCs with $\mathrm{Cu}_{2} \mathrm{O},{ }^{11}$ and subsequently used as NHC-transfer reagents. ${ }^{12}$ Such a methodology provides a versatile synthetic access to a library of NHC complexes, without the formation of the highly reactive free carbene at any stage. ${ }^{13}$ Herein, we report that this synthetic strategy can also be applied to the cyclopropenylidene series, allowing access to $\mathrm{Au}, \mathrm{Pd}, \mathrm{Ir}$ and $\mathrm{Rh}$ complexes. In addition, we show that a BAC-Cu complex has a high catalytic activity in an important catalytic transformation namely the $[3+2]$ cycloaddition of azides and alkynes.

The first step of the synthetic strategy consists of the formation of a $\mathrm{BAC}-\mathrm{Cu}^{\mathrm{I}}$ complex by reaction of the cyclopropenium chloride $\mathbf{1} \cdot \mathbf{H C l}$ with $\mathrm{Cu}_{2} \mathrm{O}$ under microwave heating. ${ }^{14}$ Indeed such a reaction benefits from short reaction times, and in this manner the desired complex [CuCl(BAC)] 2 was obtained in $92 \%$ yield after 2 hours at $80^{\circ} \mathrm{C}$ in acetonitrile (Scheme 2). It is worth mentioning that 2 is perfectly air and moisture stable, which allows for a convenient work-up procedure.

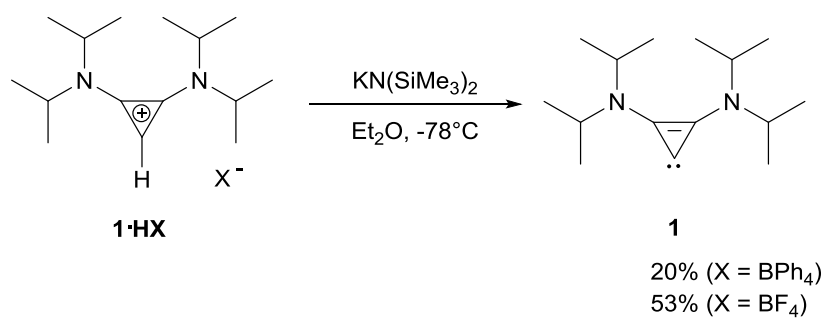

Scheme 1. Synthesis of the cyclopropenylidene $\mathbf{1}^{6}$<smiles>C=CN(CC)C1[C@H](Cl)C1(C)CC</smiles>

$1 \cdot \mathrm{HCl}$

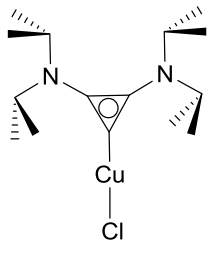

2, $92 \%$
Scheme 2. Synthesis of the Cu-BAC complex 2

The ${ }^{1} \mathrm{H}$ NMR spectrum of $\mathbf{2}$ at room temperature contains three broad signals corresponding to the ${ }^{i} \operatorname{Pr}$ groups. Upon cooling the solution to $240 \mathrm{~K}$, the signals significantly sharpen to the expected doublets and multiplet (assigned to $\mathrm{CH}_{3}$ and $\mathrm{CH}$, respectively). Such a dynamic behaviour has already been observed for the free carbene $\mathbf{1}$ and its corresponding salt $\mathbf{1} \cdot \mathbf{H B F}_{\mathbf{4}}{ }^{6 \mathrm{a}}$ The free activation energy for site exchange of the ${ }^{i} \operatorname{Pr}$ groups was found to be $53 \mathrm{~kJ} / \mathrm{mol}$ for the free carbene and $75 \mathrm{~kJ} / \mathrm{mol}$ for the cyclopropenium salt. In the case of complex 2 , a $\Delta \mathrm{G}^{\neq}$of $63.5 \mathrm{~kJ} / \mathrm{mol}$ was experimentally determined and is likely to be related to a similar dynamic process (see ESI for details). The structure of $\mathbf{2}$ was unambiguously confirmed by a single crystal X-ray diffraction study (Fig. 1). ${ }^{15}$ Complex 2 has a pseudo-linear geometry with a Cl1-Cu1-C1 angle of $175.6(2)^{\circ}$. The $\mathrm{C} 1-\mathrm{Cu} 1$ bond distance $[1.880(6) \AA]$ is strikingly shorter than previously reported $\mathrm{C}-\mathrm{Cu}$ bond lengths for $\operatorname{IPr}^{16 \mathrm{a}}(\mathrm{IPr}=(N, N$ '-bis[2,6- diisopropylphenyl]imidazol-2-ylidene) [1.953(8) $\AA$ ] and 1,2,3- 
triazol-4-ylidene $\mathrm{CuCl}$ complexes $[1.9577(16) \AA] .{ }^{17}$ This is in agreement with the strong $\sigma$-donor ability of BAC. ${ }^{1 b, 18,19}$ Its steric hindrance was assessed by calculating its $\% V_{\mathrm{Bur}}{ }^{20}$ at $1.9 \AA$ and found to be $31.6 \%$. This value is slightly larger than that of ICy $[30.5 \%$, ICy $=(N, N$ '-bis-[dicyclohexyl]imidazol-2-ylidene] and significantly smaller than that of two common NHCs, IMes [38.0\%, IMes $=(N, N$ 'bis-[2,4,6-trimethylphenyl]imidazol-2-ylidene] and $\operatorname{IPr}$ $(49.6 \%){ }^{16,21,22}$

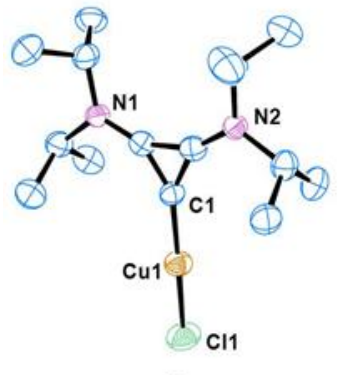

2

Figure 1. Molecular structure of 2 . Hydrogen atoms are omitted for clarity. Selected bond lengths $(\AA)$ and angles $\left({ }^{\circ}\right)$ : $\mathrm{Cu}-\mathrm{C}, 1.880(6)$; $\mathrm{Cu}-\mathrm{Cl}, 2.107(2)$; $\mathrm{C}-\mathrm{Cu}-\mathrm{Cl}, 175.6(2) .{ }^{15}$

With complex 2 in hand, its ability to transfer the carbocyclic carbene was examined. Results are summarised in Scheme 3. Four metals ( $\mathrm{Rh}, \mathrm{Ir}, \mathrm{Pd}, \mathrm{Au}$ ) belonging to Groups 9, 10 and 11 were selected to test the viability and versatility of the synthetic approach. In all cases, the transfer of the cyclopropenylidene occurs quantitatively and selectively. Spectacularly, for $\mathrm{Au}$, Ir and $\mathrm{Rh}$, the carbene transfer reaches completion within one minute at room temperature! In the case of palladium, while the transfer occurs quantitatively to form the targeted dimeric species, 4 hours and an operating temperature of $40^{\circ} \mathrm{C}$ are required to reach completion. This represents an outstandingly straightforward method compared to previously reported procedures for palladium, that for example have made use of palladium black and the $\mathrm{BAC} \cdot \mathrm{HCl}$ salt $(44 \%$ yield). ${ }^{1 \mathrm{a}, 2 \mathrm{~d}}$ The present methodology affords the desired complex with a $90 \%$ yield over the two synthetic steps. The NMR spectra of complexes 3-6 also show the presence of a dynamic phenomenon on the NMR timescale with $\Delta \mathrm{G}^{\neq}$for this process in the $50.0-64.2 \mathrm{~kJ} / \mathrm{mol}$ range (see ESI for details). All complexes were obtained in microanalytical purity and their structure was unambiguously confirmed by single crystal X-ray diffraction. ${ }^{15}$ The fact that $[\mathrm{CuCl}(\mathrm{BAC})] 2$ and $[\mathrm{AuCl}(\mathrm{BAC})] \mathbf{4}$ can be isolated in such a straightforward and pure manner is also a highlight of the approach. Indeed, all attempts to prepare $\mathbf{2}$ from the free BAC $\mathbf{1}$ failed. In the case of gold, similarly to the behaviour of the smallest CAAC carbenes, ${ }^{23} \mathrm{BAC}$ reacts with $[\mathrm{AuCl}(\mathrm{THT})]$ quantitatively affording the cationic $\left[\mathrm{Au}(\mathrm{BAC})_{2}\right]^{+}$complex, regardless of the reagent stoichiometry used (see ESI for XRD data).

The key copper synthon $\mathbf{2}$ appeared a logical choice to initially evaluate the catalytic performance of transition metal BACcontaining complexes. We chose to test its catalytic activity in the $[3+2]$ cycloaddition of azides and alkynes. ${ }^{24}$ The reaction of heptyl azide with phenyl acetylene, under mild conditions (room temperature, solvent-free), using a low catalyst loading was investigated. Comparison with $[\mathrm{Cu}(\mathrm{Cl})(\mathrm{SIMes})]$ [SIMes $=(N, N$ '-bis[2,4,6-(trimethyl)phenyl]imidazolidin-2-ylidene], which represents the state-of-the-art ${ }^{25}$ for such a reaction, showed that the cyclopropenylidene complex $\mathbf{2}$ has a higher catalytic activity than its NHC analogue. Relative kinetic profiling curves, under identical conditions, are presented in the ESI. Various substrates with a broad range of functionalities $\left(-\mathrm{NO}_{2},-\mathrm{CN},-\mathrm{OH},-\mathrm{C}=\mathrm{O}\right)$ were tested. All desired compounds were obtained with an excellent isolated yield using $0.5 \mathrm{~mol} \%$ of 2 under mild condition (solvent-free, $25^{\circ} \mathrm{C}$ ) (Scheme 4).

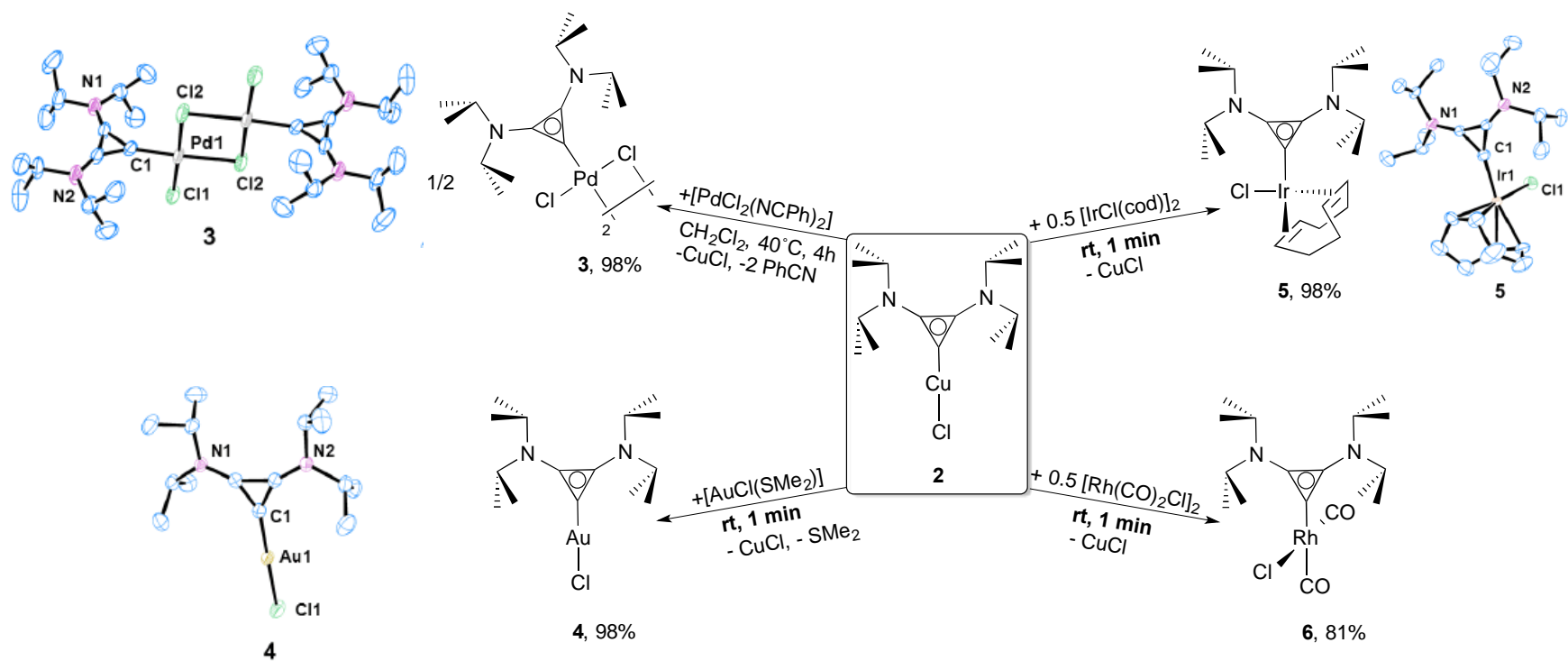

Scheme 3. Transfer of cyclopropenylidene from copper to palladium, gold, iridium and rhodium. ORTEP representations of 3-5. Hydrogen atoms are omitted for clarity. Selected bond lengths $(\AA)$ and angles $\left({ }^{\circ}\right)$ : for 3: Pd-C1, 1.926(4); Pd-Cl1, 2.2892(12); Pd-Cl2, 2.3311(12); Pd$\mathrm{Cl} 21,2.4215(11)$; for 4: Au-C1, 1.971(2); Au-Cl, 2.2843(7); C1-Au-Cl, 179.22(6); for 5: Ir-C1, 2.011(2); Ir-Cl, 2.3596(7); C1-Ir-Cl, $91.75(6) .^{15}$ 


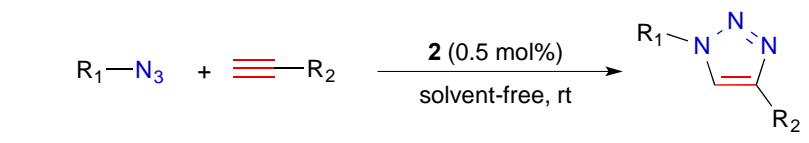

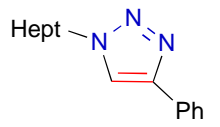

$96 \%, 5 h 20$
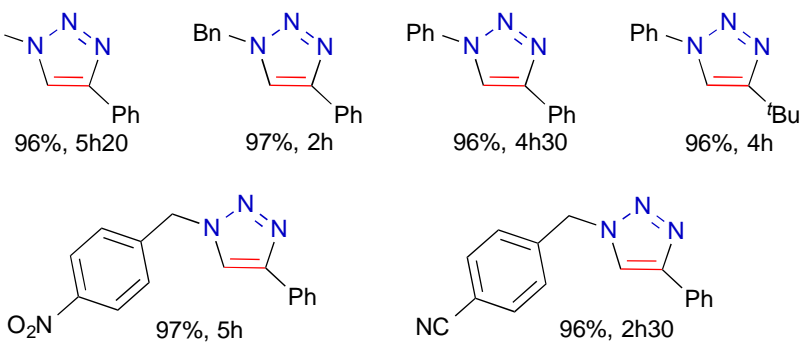

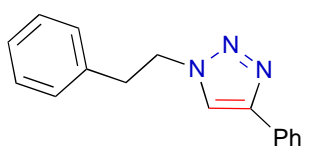

$85 \%, 7 \mathrm{~h}$
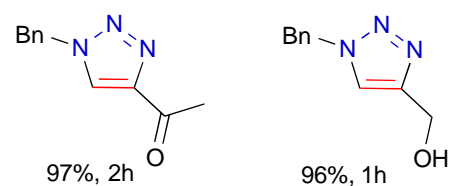

Scheme 4. Scope of the $[3+2]$ cycloaddition. Reaction conditions: 2 $(0.5 \mathrm{~mol} \%)$, azide $(1.00 \mathrm{mmol})$, alkyne $(1.10 \mathrm{mmol}), 25^{\circ} \mathrm{C}$, solventfree.

\section{Conclusions}

In conclusion, the synthesis of the first cyclopropenylidene copper(I) complex and its use as an efficient carbene transfer reagent have been achieved. The approach results in the straightforward generation of $\mathrm{Pd}$ and $\mathrm{Rh}$ complexes, as well as the first isolation of $\mathrm{Au}$ and $\mathrm{Ir}$ complexes bearing a BAC ligand. Preliminary catalytic studies of the parent $\mathrm{Cu}-\mathrm{BAC}$ complex are extremely promising and show that this ligand family may in certain instances surpass the NHC congeners. As one of the most important criteria for the development of catalysts is a versatile synthetic access to a library of complexes, we hope that the present work will encourage the study and development of highly active systems bearing cyclic carbenes other than the classical 5-membered heterocyclic standards.

The authors gratefully acknowledge the Royal Society (University Research Fellowship to CSJC) and the DOE (DEFG02-13ER16370) for financial support. We also thank the EPSRC National Spectrometry Service Centre in Swansea for HRMS analyses and Melanja Smith and Dr Tomas Lebl for assistance with variable-temperature NMR experiments.

\section{Notes and references}

${ }^{a}$ Y. D. Bidal, M. Lesieur, Dr. D. B. Cordes, Prof. A. M. Z. Slawin, Dr. C. S. J. Cazin*

EaStCHEM School of Chemistry

University of St Andrews

St Andrews, KY16 9ST, UK

E-mail: cc111@st-andrews.ac.uk

${ }^{b}$ Dr. M. Melaimi, Prof. G. Bertrand*

UCSD-CNRS Joint Research Laboratory (UMI 3555),

Department of Chemistry and Biochemistry,
University of California, San Diego, La Jolla, CA 92093-0343, USA. Electronic Supplementary Information (ESI) available: Synthesis and characterisation of ligand precursor, complexes, azide substrates and catalysis products, general procedure for catalysis, VT-NMR experiments, $\Delta \mathrm{G}^{\neq}$and $\% \mathrm{~V}_{\mathrm{Bur}}$ determination, NMR spectra of complexes and catalysis products, and crystal data for $\mathbf{2 - 5}$ and $\left[\mathrm{Au}(\mathrm{BAC})_{2}\right]+\mathrm{OTf}^{-}$See DOI: $10.1039 / \mathrm{c} 000000 \mathrm{x} /$

1 a) K. Öfele, E. Tosh, C. Taubmann, W. A. Herrmann, Chem. Rev., 2009, 109, 3408-3444; b) M. Melaimi, M. Soleilhavoup, G. Bertrand, Angew. Chem. Int. Ed., 2010, 49, 8810-8849; c) D. Martin, M. Melaimi, M. Soleilhavoup, G. Bertrand, Organometallics, 2011, 30, 5304-5313; d) S. J. Connon, Angew. Chem. Int. Ed., 2014, 53, $1203-$ 1205.

2 a) R. Weiss, C. Priesner, H. Wolf, Angew. Chem. Int. Ed. Engl., 1978, 17, 446-447; b) R. Weiss, M. Hertel, H. Wolf, Angew. Chem. Int. Ed. Engl., 1979, 18, 473-474; c) Z. Yoshida, H. Konishi, S. Sawada, H. Ogoshi, J. Chem. Soc. Chem. Commun., 1977, 850-851; d) H. Konishi, S. Matsumoto, Y. Kamitori, H. Ogoshi, Z. Yoshida, Chem. Lett., 1978, 241-244; e) Z. Yoshida, Pure Appl. Chem., 1982, 54, 1059-1074; f) S. Miki, T. Ohno, H. Iwasaki, Z. Yoshida, J. Phys. Org. Chem., 1988, 1, 333-349.

3 a) K. Öfele, J. Organomet. Chem., 1970, C9-C11; b) R. Weiss, C. Priesner, Angew. Chem. Int. Ed. Engl., 1978, 17, 457-458.

4 a) C. W. Rees, E. von Angerer, J. Chem. Soc. Chem. Commun., 1972, 420; b) R. Gompper, E. Bartmann, Angew. Chem. Int. Ed. Engl., 1978, 17, 456-457; c) M. Tamm, A. Grzegorzewski, F. E. Hahn, J. Organomet. Chem., 1995, 501, 309-313; d) H. Schumann, M. Glanz, F. Girgsdies, F. E. Hahn, M. Tamm, A. Grzegorzewski, Angew. Chem. Int. Ed. Engl., 1997, 36, 2232-2234.

5 a) L. H. Gade, H. Memmler, U. Kauper, A. Schneider, S. Fabre, I. Bezougli, M. Lutz, C. Galka, I. J. Scowen, M. McPartlin, Chem. Eur. J., 2000, 6, 692-708; b) A. Kozma, J. Petuškova, C. W. Lehmann, M. Alcarazo, Chem. Commun., 2013, 49, 4145-4147.

6 a) V. Lavallo, Y. Canac, B. Donnadieu, W. W. Schoeller, G. Bertrand, Science, 2006, 722-724; b) V. Lavallo, Y. Canac, B. Donnadieu, W. W. Schoeller, G. Bertrand, Angew. Chem. Int. Ed., 2006, 45, 6652-6655.

7 G. Kuchenbeiser, B. Donnadieu, G. Bertrand, J. Organomet. Chem., 2008, 693, 899-904.

8 D. Holschumacher, C. G. Hrib, P. G. Jones, M. Tamm, Chem. Commun., 2007, 3661-3663.

9 a) D. F. Wass, M. F. Haddow, T. W. Hey, A. G. Orpen, C. A. Russell, R. L.Wingad, M. Green, Chem. Commun., 2007, 2704-2706; b) D. F. Wass, T. W. Hey, J. Rodriguez-Castro, C. A. Russell, I. V. Shishkov, R. L. Wingad, M. Green, Organometallics, 2007, 26, 4702-4703; c) W. A. Herrmann, K. Öfele, C. Taubmann, E. Herdweck, S. D. Hoffmann, J. Organomet. Chem., 2007, 692, 38463854; d) C. Taubmann, E. Tosh, K. Öfele, E. Herdtweck, W. A. Herrmann, J. Organomet. Chem., 2008, 693, 2231-2236; e) H. A. Malik, G. J. Sormunen, J. Montgomery, J. Am. Chem. Soc., 2010, 132, 6304-6305; f) S. K. Rodrigo, H. Guan, J. Org. Chem., 2012, 77, 8303-8309.

10 a) S. P. Nolan, N-Heterocyclic Carbenes in Synthesis, Wiley-VCH, New York, 2006; b) F. Glorius, N-Heterocyclic Carbenes in Transition Metal Catalysis, Topic in Organometallic Chemistry, Vol. 
21, Springer-Verlag, Berlin-Heidelberg, 2007; c) C. S. J. Cazin, NHeterocyclic Carbenes in Transition Metal Catalysis and Organocatalysis, Springer, London, 2011; d) S. P. Nolan, NHeterocyclic Carbenes - Effective Tools for Organometallic Synthesis, Wiley-VCH, Mannheim, 2014, in press; e) P. de Frémont, N. Marion, S. P. Nolan, Coord. Chem. Rev., 2009, 253, 862-892; f) S. Díez-González, N. Marion, S. P. Nolan, Chem. Rev., 2009, 109, 3612-3676.

11 C. A. Citadelle, E. Le Nouy, F. Bisaro, A. M. Z. Slawin, C. S. J. Cazin, Dalton Trans., 2010, 39, 4489-4491.

12 a) G. Venkatachalam, M. Heckenroth, A. Neels, M. Albrecht, HeIv. Chim. Acta, 2009, 92, 1034-1045; b) M. R. L. Furst, C. S. J. Cazin, Chem. Commun., 2010, 46, 6924-6925.

13 See for example: a) C. Chen, H. Qiu, W. Chen, J. Organomet. Chem., 2012, 696, 4166-4172; b) A. C. Badaj, G. G. Lavoie, Organometallics, 2012, 31, 1103-1111; c) J. Al Thagfi, G. G. Lavoie, Organometallics, 2012, 31, 2463-2469; d) J. Al Thagfi, G. G. Lavoie, Organometallics, 2012, 31, 7351-7358; e) R. Tan, F. S. N. Chiu, A. Hadzovic, D. Song, Organometallics, 2012, 31, 2184-2192; f) E. K. Bullough, M. A. Little, C. E. Willans, Organometallics, 2013, 32, 570-577; g) J. Mormul, M. Steimann, U. Nagel, Eur. J. Inorg. Chem., 2014, 1389-1393.

14 This reaction can also be carried out using conventional heating. See ESI for details.

15 CCDC 1012888 (2), CCDC 1012889 (3), CCDC 1012890 (4), CCDC 1012887 (5) contain the supplementary crystallographic data for $\mathbf{2 - 5}$. CCDC 1020907 contains supplementary crystallographic data for $\left[\mathrm{Au}(\mathrm{BAC})_{2}\right]^{+} \mathrm{OTf}$ complex. These data can be obtained free of charge from the Cambridge Crystallographic Data Centre via www.ccdc.cam.ac.uk/data request/cif.

16 a) H. Kaur, F. Kauer Zinn, E. D. Stevens, S. P. Nolan, Organometallics, 2004, 23, 1157-1160; b) S. Díez-González, E. D. Stevens, S. P. Nolan, Chem. Commun., 2008, 4747-4749.

17 X. Yan, J. Bouffard, G. Guisado-Barrios, B Donnadieu, G. Bertrand, Chem. Eur. J., 2012, 18, 14627-14631.

18 J. S. Bandar, T. H. Lambert, Synthesis, 2013, 45, 2485-2498.

19 D. J. Nelson, S. P. Nolan, Chem. Soc. Rev., 2013, 42, 6723-6753.

$20 \%$ VBur were calculated from the web application SambVca.

21 S. Díez-González, E. C. Escudero-Adán, J. Benet-Buchholz, E. D. Stevens, A. M. Z. Slawin, S. P. Nolan, Dalton Trans., 2010, 39, 7595-7606.

22 S. Díez-González, H. Kaur, F. Kauer Zinn, E. D. Stevens, S. P. Nolan, J. Org. Chem., 2005, 70, 4784-4796.

23 G. D. Frey, R. D. Dewhurst, S. Kousar, B. Donnadieu, G. Bertrand, J. Organomet. Chem., 2008, 693, 1674-1682. For a simplified access to aza-CAAC complexes, see: R. Manzano, F. Rominger, A. S. K. Hashmi, Organometallics, 2013, 32, 2199-2203; R. Manzano, T. Wurm, F. Rominger, A. S. K. Hashmi, Chem. Eur. J., 2014, 20, 6844-6848.

24 For reviews on Click Chemistry, see for examples: a) H. C. Kolb, M. G. Finn, K. B. Sharpless, Angew. Chem. Int. Ed. Engl. 2001, 40, 2004-2021; b) J. E. Hein, V. V. Fokin, Chem. Soc. Rev., 2010, 39, 1302-1315.

25 For neutral $\mathrm{Cu}$ complexes in [3+2] alkyne-azide cycloaddition see: a) S. Díez-González, A. Correa, L. Cavallo, S. P. Nolan, Chem. Eur. J., 2006, 12, 7558-7564; b) S. Díez-González, S. P. Nolan, Synlett,
2007, 14, 2158-2167; c) P. Li, L. Wang, Y. Zhang, Tetrahedron, 2008, 64, 10825-10830; d) M.-L. Teyssot, A. Chevry, M. Traïkia, M. El-Ghozzi, D. Avignant, A. Gautier, Chem. Eur. J., 2009, 15, 63226326; e) M.-L. Teyssot, L. Nauton, J.-L. Canet, F. Cisnetti, A. Chevry, A. Gautier, Eur. J. Org. Chem., 2010, 3507-3515; f) J. D. Egbert, C. S. J. Cazin, S. P. Nolan, Catal. Sci. Technol., 2013, 3, $912-$ 926 